\title{
Using propensity scores to estimate the effectiveness of maternal and newborn interventions to reduce neonatal mortality in Nigeria
}

Jamie Perin ${ }^{1,2^{*}}$ D, Alain K. Koffi ${ }^{1}$, Henry D. Kalter ${ }^{1}$, Joseph Monehin ${ }^{3}$, Adeyinka Adewemimo ${ }^{4}$, John Quinley ${ }^{5}$ and Robert E. Black ${ }^{1}$

\begin{abstract}
Background: Nigeria is the largest country in sub-Saharan Africa, with one of the highest neonatal mortality rates and the second highest number of neonatal deaths in the world. There is broad international consensus on which interventions can most effectively reduce neonatal mortality, however, there is little direct evidence on what interventions are effective in the Nigerian setting.

Methods: We used the 2013 Nigeria Demographic and Health Survey (NDHS) and the follow-up 2014 Verbal and Social Autopsy study of neonatal deaths to estimate the association between neonatal survival and mothers' and neonates' receipt of 18 resources and interventions along the continuum of care with information available in the NDHS. We formed propensity scores to predict the probability of receiving the intervention or resource and then weighted the observations by the inverse of the propensity score to estimate the association with mortality. We examined all-cause mortality as well as mortality due to infectious causes and intrapartum related events.
\end{abstract}

Results: Among 19,685 livebirths and 538 neonatal deaths, we achieved adequate balance for population characteristics and maternal and neonatal health care received for 10 of 18 resources and interventions, although inference for most antenatal interventions was not possible. Of ten resources and interventions that met our criteria for balance of potential confounders, only early breastfeeding was related to decreased all-cause neonatal mortality (relative risk $0.42,95 \% \mathrm{Cl} 0.32-0.52, p<0.001$ ). Maternal decision making and postnatal health care reduced mortality due to infectious causes, with relative risks of 0.29 (95\% Cl $0.09-0.88 ; 0.030)$ and $0.46(0.22-0.95 ; 0.037)$, respectively. Early breastfeeding and delayed bathing were related to decreased mortality due to intrapartum events, although these are not likely to be causal associations.

(Continued on next page)

\footnotetext{
* Correspondence: jperin@jhu.edu

'Institute for International Programs, Johns Hopkins Bloomberg School of Public Health, Baltimore, MD, USA

${ }^{2}$ Center for Child and Community Health Research, Department of Pediatrics, Johns Hopkins School of Medicine, Baltimore, MD, USA

Full list of author information is available at the end of the article
}

(C) The Author(s). 2020 Open Access This article is licensed under a Creative Commons Attribution 4.0 International License, which permits use, sharing, adaptation, distribution and reproduction in any medium or format, as long as you give appropriate credit to the original author(s) and the source, provide a link to the Creative Commons licence, and indicate if changes were made. The images or other third party material in this article are included in the article's Creative Commons licence, unless indicated otherwise in a credit line to the material. If material is not included in the article's Creative Commons licence and your intended use is not permitted by statutory regulation or exceeds the permitted use, you will need to obtain permission directly from the copyright holder. To view a copy of this licence, visit http://creativecommons.org/licenses/by/4.0/ The Creative Commons Public Domain Dedication waiver (http://creativecommons.org/publicdomain/zero/1.0/) applies to the data made available in this article, unless otherwise stated in a credit line to the data. 
(Continued from previous page)

Conclusion: Access to immediate postnatal care and women's autonomous decision-making have been among the most effective interventions for reducing neonatal mortality in Nigeria. As neonatal mortality increases relative to overall child mortality, accessible interventions are necessary to make further progress for neonatal survival in Nigeria and other low resource settings.

Keywords: Nigeria, Epidemiological transition, Effectiveness, Causal inference

\section{Background}

Nigeria is the largest country in sub-Saharan Africa, with a neonatal mortality rate in 2016 at 36 deaths per 1000 livebirths and the second highest number of neonatal deaths in the world [1]. Although neonatal mortality in Nigeria is in decline, more progress is needed before the Sustainable Development Goal (SDG) target of 12 neonatal deaths per 1000 live births by 2030 can be met [2]. Birth asphyxia, sepsis, and complications of prematurity are the predominant causes of newborn mortality, which over time is an increasing proportion of under-five mortality in Nigeria as survival for children aged 1 to 59 months improves [1, 3]. Public health research and historic rates of newborn survival suggest that neonatal mortality can be reduced even in low resource settings [4]. Although neonates are a vulnerable population, there are cost-effective resources and interventions that promote survival without specialized technology used in high income countries for intensive neonatal care.

There is broad international consensus on which interventions can most effectively reduce neonatal mortality, including intermittent preventive treatment of malaria in pregnancy (IPTp), tetanus toxoid immunization, iron/ folate supplementation [4], corticosteroids for premature births [5], active management of labor [6], early skin-toskin contact [7], early breastfeeding initiation [8], and use of $4 \%$ chlorhexidine gel for cord care [9] or dry cord care in the absence of chlorhexidine [10]. In addition to these specific interventions for neonatal survival, it is expected that contact of both expectant mothers and neonates with local health systems will benefit neonates through the management of maternal complications and neonatal illnesses during antenatal care for pregnant women (ANC) [11], delivery in a health facility [12], skilled birth attendance (SBA) [13], and postnatal care for very young neonates (PNC) $[14,15]$. There are other potentially actionable factors that may independently influence neonatal mortality such as women's empowerment and the expected travel distance to health care [16, 17].

The national guidelines on maternal health in Nigeria recommend key interventions be provided to all pregnant women as part of antenatal and delivery care services [18]. These include tetanus toxoid immunization, iron-folate supplementation and active management of the third stage of labor. Post-partum, recommended interventions directed at improving newborn survival include early skinto-skin contact, early initiation of breastfeeding, Vitamin $\mathrm{K}$ injection and chlorhexidine application to the umbilical cord. However, not all recommended interventions are widely available in all areas of Nigeria [19].

Despite recommendations from the Nigerian Federal Ministry of Health that are founded on broad-based public health studies, there are few local studies on the effects of key interventions on neonatal survival. It is possible that for health system-related or other factors, some interventions may be more or less effective than expected from primary research [20]. Recent household surveys, despite limitations, have the potential to shed light on the effectiveness of interventions for neonatal survival in Nigeria, and to identify interventions that are most effectively translated to the local context and with the greatest potential to reduce neonatal mortality. We aimed to robustly examine interventions for neonatal survival in the Nigerian setting.

\section{Methods}

We compared neonatal mortality for those that received standard public health interventions or with health resources to those who did not based on the 2013 Nigeria Demographic and Health Survey (NDHS) and the follow-up 2014 Nigeria Verbal and Social Autopsy (VASA) Study [21, 22]. The instrument used in this study is publicly available in four languages [23]. We aimed to estimate the effectiveness of the selected interventions and resources as close as possible to what would be their causal effect. Studies using observational data to estimate effectiveness and make causal interpretations of effects often employ the probability of receiving treatment or propensity scores to adjust for potential confounders instead of regression adjustment. We used propensity scores to weight survey response so that populations with interventions or resources were more similar to those without, with respect to the covariatepredicted probability of having those interventions or resources [24]. We separately estimated the effectiveness for each of eighteen interventions and resources with potential to reduce neonatal mortality, while attempting to control for external factors, including other interventions and resources available to mothers and neonates. 
We aimed to estimate the effectiveness of each intervention and resource independent of other factors.

\section{Data}

The 2013 NDHS was a multistage sample survey that used standardized methods to select households for national representation and was made publicly available for health researchers upon completion. In the first stage, census enumeration areas or clusters were selected with probability proportional to size provided by a recent population census, in several regional strata. In the second stage, complete household listings were made for the selected clusters, and households were then selected systematically with equal probability. Most interventions and resources for neonatal survival were only documented in the NDHS for the most recent birth in each household by design, so we included only the most recent household births in the five years prior to the survey [25]. The VASA surveyed households where a recent neonatal death was identified in the full birth history of the NDHS, so that additional information could be recorded. If more than one child under the age of five was indicated from the NDHS to have died in a household in the past five years, the VASA study randomly selected only one death for verbal authopsy, meaning that some neonatal deaths were not queried for cause of death. A detailed description of the methods and results from both the NDHS and VASA surveys are described in reports by the National Population Commission of Nigeria [21, 22]. Survival among neonates born in the five years prior to the 2013 NDHS was approximated using the full birth history from the women's questionnaire. Cause of death was defined by the VASA study's expert algorithm cause assignment [22]. For maximum consistency between information relating to those who died compared to survivors, we used the NDHS questionnaire for whether a neonate or mother received an intervention or had access to a resource. The VASA survey was used to incorporate the cause of death determined by verbal autopsy.

We selected interventions and resources for this analysis based on the Every Newborn Action Plan (ENAP) for pregnant women and neonates [26]. Some interventions recommended by ENAP were not documented in the 2013 NDHS survey, including active management of labor, corticosteroids for premature births, neonatal resuscitation, and antibiotic use for sick neonates, and so these could not be examined [27]. These interventions and resources span the continuum of care for neonatal survival, including the antenatal period, for example, whether women are primary decision maker for accessing health care, as well as whether women received antenatal care or specific antenatal interventions such as having their blood or urine tested. We chose interventions and resources to also cover the circumstances of birth, including where the neonate was delivered, whether a skilled attendant was present, and the mode of delivery. We also covered the immediate postnatal period, to include early breastfeeding, thermal care (drying, skin-to-skin contact and delayed bathing) as well as whether the neonate received postnatal care within two days of delivery. All interventions and resources included in this analysis are shown in Table 1.

\section{Potential confounding factors}

In our examination of confounding, we aimed to include demographics factors that we expected would influence whether interventions or resources were available as well as neonatal survival. These factors recorded in the NDHS included birth order, whether each birth was singleton or multiple, mother's and father's education, maternal age at first birth, maternal age at time of index birth, whether the mother was married, urban or rural residence, household wealth quintile, and whether the surveyed household reported a prior neonatal death. We also included whether they received or had other interventions and resources as potential confounders. Some interventions were only measured in home births by the NDHS design (skin-to-skin contact, drying, dry umbilical cord treatment and delayed bathing for $24 \mathrm{~h}$ ). We did not include these home interventions as confounders when estimating the effectiveness of interventions and resources measured both in facility and home births because of this limited population.

There were additional factors of interest likely to be related to whether an intervention or resource was available, or to the risk of neonatal mortality, that were not available due to limitations from the NDHS. For example, intrapartum complications such as preterm delivery and obstructed labor were not documented by the NHDS, and so were not available in this analysis.

\section{Statistical methods}

We expected the differences between those who received interventions or had access to resources and those who did not to be complex [28], so we approached potential confounding carefully. Analysis using regression based methods to adjust for confounders can be subject to bias [24] and yield misleading results in circumstances with extreme confounding [29]. We aimed to estimate the effectiveness of interventions and resources while reducing bias from confounding in this population with inverse probability weights using a propensity score of the probability of receiving an intervention or resource, conditional on observed factors [30].

We used logistic regression to estimate the propensity score for each intervention or resource separately, including survey sample weights as recommended for 
Table 1 Description of maternal and newborn health interventions and resources expected to influence newborn survival. Estimated coverage is shown for 19,685 livebirths in the five years prior to survey, or among 12,157 livebirths occurring at home, for the most recent birth for each survey respondent in the Nigeria 2013 DHS survey

\begin{tabular}{|c|c|c|}
\hline Resource/Intervention & Definition / Survey questionnaire item & $\begin{array}{l}\text { Estimated Coverage } \\
\text { (2013 Nigeria DHS) }\end{array}$ \\
\hline \multicolumn{3}{|l|}{ Resources } \\
\hline Mother is primary decision maker & Mother usually makes decisions about health care for herself. & $3 \%$ \\
\hline Distance is not a problem for mother's health care & $\begin{array}{l}\text { When mother is sick and wants to get medical advice or } \\
\text { treatment, distance to the health facility is not a big problem. }\end{array}$ & $69 \%$ \\
\hline \multicolumn{3}{|l|}{ Interventions delivered in the antenatal period } \\
\hline ANC 1 visit & $\begin{array}{l}\text { One or more antenatal care visits during pregnancy with a } \\
\text { skilled provider (doctor, nurse, midwife, or community } \\
\text { health worker). }\end{array}$ & $60 \%$ \\
\hline ANC 4 visits & $\begin{array}{l}\text { Four or more antenatal care visits during pregnancy with any } \\
\text { provider. }\end{array}$ & $51 \%$ \\
\hline At least one ANC intervention & $\begin{array}{l}\text { During pregnancy, mother had blood pressure measured, } \\
\text { gave a urine or blood sample, or was told about things to } \\
\text { look out for that might suggest problems during pregnancy. }\end{array}$ & $62 \%$ \\
\hline Four ANC interventions & $\begin{array}{l}\text { During pregnancy, mother had blood pressure measured, } \\
\text { gave a urine and blood sample, and also was told about } \\
\text { things to look out for that might suggest problems during } \\
\text { pregnancy. }\end{array}$ & $37 \%$ \\
\hline Tetanus Toxoid during pregnancy & $\begin{array}{l}\text { During pregnancy mother was given an injection to prevent } \\
\text { the baby from getting tetanus. }\end{array}$ & $59 \%$ \\
\hline Iron/folate during pregnancy & During pregnancy mother was given iron tablets or iron syrup. & $63 \%$ \\
\hline Malaria preventive therapy during pregnancy & $\begin{array}{l}\text { During this pregnancy, mother took any drug to } \\
\text { prevent malaria. }\end{array}$ & $48 \%$ \\
\hline \multicolumn{3}{|l|}{ Interventions in labor and delivery } \\
\hline Institutional birth & Infant was delivered at hospital, health center, or health clinic. & $37 \%$ \\
\hline Skilled attendant during birth & Delivery was assisted by doctor, nurse, or midwife. & $40 \%$ \\
\hline Delivered by C-Section & Delivery was conducted by Caesarean-Section. & $2 \%$ \\
\hline \multicolumn{3}{|l|}{ Interventions delivered in the postnatal period } \\
\hline Dry cord care (nothing on cord) ${ }^{a}$ & $\begin{array}{l}\text { No substance was applied to the umbilical cord after it } \\
\text { was cut. }\end{array}$ & $64 \%$ \\
\hline Neonate dried after birth ${ }^{a}$ & Infant dried before delivery of the placenta. & $28 \%$ \\
\hline Skin-to-skin contact after birth ${ }^{a}$ & $\begin{array}{l}\text { Immediately after birth, baby was put directly on the bare } \\
\text { skin of mother's chest. }\end{array}$ & $9 \%$ \\
\hline Early breastfeeding (within one hour) & Baby was put to the breast within one hour of birth. & $34 \%$ \\
\hline Delayed bathing $24 \mathrm{~h}$ or more ${ }^{\mathrm{a}}$ & Not given a bath in the first $24 \mathrm{~h}$ after birth. & $4 \%$ \\
\hline PNC within 2 days of births & $\begin{array}{l}\text { Baby received care within two days of delivery from any } \\
\text { provider (e.g. to check cord, baby's temperature, or whether } \\
\text { baby feeding well). }\end{array}$ & $15 \%$ \\
\hline
\end{tabular}

${ }^{a}$ Only reported for home deliveries

propensity scores in complex surveys [31, 32]. We used these estimated propensity scores to weight responses with inverse probability of treatment, creating two groups, based on intervention receipt, which on average were expected to be similar in demographic factors and other interventions used to estimate the propensity score [33]. We verified this balance of potential confounders graphically after weighting with propensity scores by examining the standardized difference. The standardized difference was defined as the difference in means between treatment groups divided by the overall standard deviation. We used a cutoff for the standardized difference of 0.2 or lower to determine adequante balance of potential confounders [34].

We examined the effectiveness of interventions to prevent all cause neonatal mortality as well as for neonatal mortality due to infectious causes (sepsis, diarrhea, tetanus, pneumonia and meningitis, combined) and for 
mortality due to intrapartum-related events (IPRE), i.e., birth injury or asphyxia. To estimate relative all-cause, infection-specific, and IPRE-specific mortality, we used Poisson regression with propensity score weighted repsonses to estimate the effectiveness of interventions and resources [35], incorporating the survey design and the sampling probability as weights and primary sampling units as clusters [36, 37]. We used a Poisson regression model with robust variance estimation as recommended by Zou (2004) [38]. This weighted relative risk was also regression adjusted for the same factors as used in estimating the propensity score per the standard recommendation [33]. We used the product of the propensity score and the sampling weight as a composite weight in this analysis [32]. We compared this weighted estimate with an unweighted estimate that was also adjusted for demographics and other interventions in the framework of Poisson regression while incorporating the multi-stage NDHS survey design. We did not control for multiple comparisons. Data used in this analysis is publicly available for research purposes from http:// www.dhsprogram.com. All analysis was conducted using the twang and survey packages in $R$ version 3.4.0 [39]. A summary of considerations for analysis is shown in detail in Additional file 5.

\section{Results}

There were 19,685 most recent live births by household surveyed in the five years prior to the 2013 NDHS where interventions and resources of interest were measured. Among these, estimated coverage of interventions and resources for newborn survival varied from $2 \%$ of women with caesarean delivery, to $64 \%$ of mothers who received iron or folate during their pregnancy, shown in Table 1. Additional file 1 shows the STROBE Diagram for those contributing to analysis. Demographic factors were crudely associated with neonatal mortality among surveyed births (Table 2). Singleton birth, later birth order and having no prior neonatal death in the household were strongly related to higher survival rates, while area of residence, wealth quintile, father's education, mother's education, mother's marital status, mother's age at first birth and mother's age at index birth were not associated with newborn survival.

We observed considerable differences in demographic factors and especially other interventions and resources when describing those who received a specific intervention compared to those who did not. Every one of our eighteen interventions and resources had at least one potential confounder with a standardized difference above 0.2 prior to weighting with a propensity score, indicating a potential for biased associations [40]. Prior to using weights, early breastfeeding had the smallest standardized differences, where none exceeded 0.4. Facility delivery and skilled birth attendance had the largest standardized differences prior to weighting, exceeding 1.5.

Weighting surveyed births with propensity scores greatly improved the overall similarity of comparison groups. We were able to achieve optimum comparison groups for ten of eighteen interventions and resources. A summary of the balance of confounding factors between groups is shown in Fig. 1 for six interventions and resources both before and after weighting with propensity scores. Balance is shown as the average difference between those who received the intervention or resource versus those who did not divided by overall standard error (the standardized difference). Balance for all potential confounders for all 18 interventions and resources is shown in Additional file 2. Less than optimum balance of potential confounders was achieved after weighting with propensity scores for eight interventions: one ANC visit with a skilled provider (ANC1), four ANC visits with any provider, at least one ANC intervention, four ANC interventions, tetanus toxoid during pregnancy, institutional delivery, SBA, and caesarean delivery. Our ability to make unbiased inferences for these eight interventions is thus limited [40]. In general, balance was not achieved for neither demographic factors nor other interventions and resources. Unbalanced demographic factors included wealth quintile and paternal education (when comparing ANC1, tetanus toxoid, ANC4, any ANC content, four ANC interventions and facility birth), while unbalanced interventions included iron/folate receipt and tetanus toxoid vaccination during pregnancy (when comparing SBA, ANC1, ANC4, any ANC content and four ANC interventions).

The 19,685 surveyed births in the last five years included 538 neonatal deaths, although 212 (39\%) of these were not covered in the VASA study and thus were not examined for underlying cause of death. Among 326 neonatal deaths with estimated cause of death, 171 (52\%) were caused by sepsis, diarrhea, tetanus, pneumonia or meningitis, and $74(23 \%)$ were due to IPRE [41]. All causes of death as well as ages at death among neonates are shown in Additional file 3.

We estimated crude associations between mortality and eighteen interventions and resources, as well as regression-adjusted associations, and associations using a propensity score for the ten interventions and resources where the standardized difference for all confounding factors was 0.2 or lower. For all-cause neonatal mortality, both unweighted and propensity score weighted relative risks are shown in Table 3 and Fig. 2 for ten interventions with adequate balance of confounding factors. Crude associations are shown in Additional file 4 . There were three interventions with apparent relationships with mortality after weighting with propensity 
Table 2 Summary of potential confounders for maternal and newborn health interventions and resources and their associations with all-cause neonatal mortality in the Nigeria 2013 DHS survey, among deaths and survivors, for 19,685 livebirths in the five years prior to survey

\begin{tabular}{|c|c|c|c|c|c|c|}
\hline & \multirow[b]{2}{*}{ Level } & \multirow{2}{*}{$\begin{array}{l}\text { Overall } \\
(n=19,685) \\
\text { Percent }\end{array}$} & \multirow{2}{*}{$\begin{array}{l}\text { Deaths } \\
(n=538) \\
\text { Percent }\end{array}$} & \multirow{2}{*}{$\begin{array}{l}\text { Survivors } \\
(n=19,147) \\
\text { Percent }\end{array}$} & \multicolumn{2}{|c|}{ Crude Relative Risk } \\
\hline & & & & & Est & $p$ \\
\hline \multirow[t]{3}{*}{ Birth order } & first & $18 \%$ & $25 \%$ & $18 \%$ & (ref) & $<0.001^{a}$ \\
\hline & 2nd-4th & $45 \%$ & $35 \%$ & $45 \%$ & 0.984 & \\
\hline & 5 th + & $37 \%$ & $40 \%$ & $37 \%$ & 0.991 & \\
\hline Multiple birth & & $2 \%$ & $8 \%$ & $2 \%$ & 1.099 & $<0.001$ \\
\hline \multirow[t]{3}{*}{ Mother's education } & None & $48 \%$ & $47 \%$ & $48 \%$ & (ref) & $0.489^{b}$ \\
\hline & Primary & $19 \%$ & $24 \%$ & $19 \%$ & 1.007 & \\
\hline & Secondary & $33 \%$ & $29 \%$ & $33 \%$ & 0.997 & \\
\hline \multirow[t]{4}{*}{ Father's education } & None & $38 \%$ & $38 \%$ & $38 \%$ & (ref) & $0.806^{b}$ \\
\hline & Primary & $18 \%$ & $18 \%$ & $18 \%$ & 1.001 & \\
\hline & Secondary & $41 \%$ & $40 \%$ & $41 \%$ & 0.999 & \\
\hline & Missing & $3 \%$ & $4 \%$ & $3 \%$ & 1.008 & \\
\hline \multirow[t]{5}{*}{ Mother's age at first birth } & $<15$ & $8 \%$ & $7 \%$ & $8 \%$ & (ref) & $0.030^{\mathrm{a}}$ \\
\hline & $15-17$ & $32 \%$ & $30 \%$ & $32 \%$ & 1.002 & \\
\hline & $18-24$ & $48 \%$ & $47 \%$ & $48 \%$ & 1.002 & \\
\hline & $25-34$ & $12 \%$ & $15 \%$ & $12 \%$ & 1.009 & \\
\hline & $35+$ & $0 \%$ & $1 \%$ & $0 \%$ & 1.067 & \\
\hline \multirow[t]{5}{*}{ Mother's age at index birth } & $<15$ & $0 \%$ & $0 \%$ & $0 \%$ & (ref) & $0.027^{\mathrm{a}}$ \\
\hline & $15-17$ & $6 \%$ & $8 \%$ & $6 \%$ & 1.009 & \\
\hline & $18-24$ & $31 \%$ & $26 \%$ & $31 \%$ & 0.995 & \\
\hline & $25-34$ & $44 \%$ & $44 \%$ & $44 \%$ & 0.999 & \\
\hline & $35+$ & $18 \%$ & $22 \%$ & $18 \%$ & 1.004 & \\
\hline Mother married & & $92 \%$ & $92 \%$ & $92 \%$ & 1.001 & 0.822 \\
\hline \multirow[t]{2}{*}{ Area } & Urban & $36 \%$ & $32 \%$ & $36 \%$ & (ref) & \\
\hline & Rural & $64 \%$ & $68 \%$ & $64 \%$ & 1.005 & 0.095 \\
\hline \multirow[t]{5}{*}{ Wealth Quintile } & Poorest & $23 \%$ & $23 \%$ & $23 \%$ & (ref) & $0.224^{b}$ \\
\hline & Poorer & $22 \%$ & $27 \%$ & $22 \%$ & 1.006 & \\
\hline & Middle & $19 \%$ & $16 \%$ & $19 \%$ & 0.996 & \\
\hline & Richer & $18 \%$ & $18 \%$ & $18 \%$ & 1.000 & \\
\hline & Richest & $18 \%$ & $16 \%$ & $18 \%$ & 0.997 & \\
\hline Prior neonatal death in household & & $16 \%$ & $30 \%$ & $15 \%$ & 1.029 & $<0.001$ \\
\hline
\end{tabular}

aikelihood ratio test for association in any comparison with reference level

${ }^{\mathrm{b}}$ Test for association with mortality assuming consistent trend with increasing levels

scores, although not all in the expected direction: distance not being a problem for receiving health care (relative risk 1.30, 95\% CI 1.03-1.67), dry cord care (1.40, 95\% CI 1.04-1.89) and early breast feeding (0.41, 95\% CI 0.32-0.52). All of these in addition to PNC were also associated with all-cause neonatal mortality prior to weighting with propensity scores.

We also examined neonatal mortality due to infectious causes (Table 4) for ten interventions and resources that were balanced for potential confounders after weighting with propensity scores. Two interventions protected against mortality due to infections after weighting with propensity scores: mother is primary decision maker for her health care (relative risk 0.29, 95\% CI $0.09-0.88)$ and PNC (0.46, 95\% CI 0.22-0.95). There were no interventions having associations with mortality due to infectious causes prior to weighting with propensity scores. 
(a)
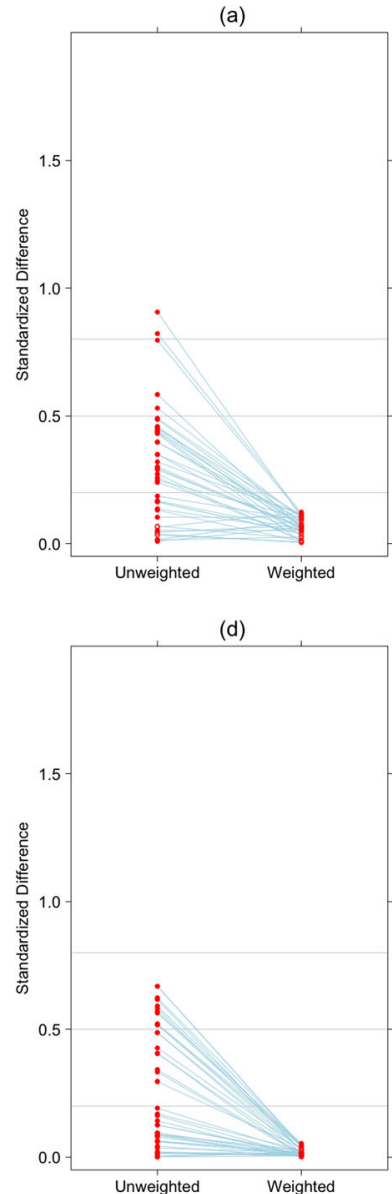

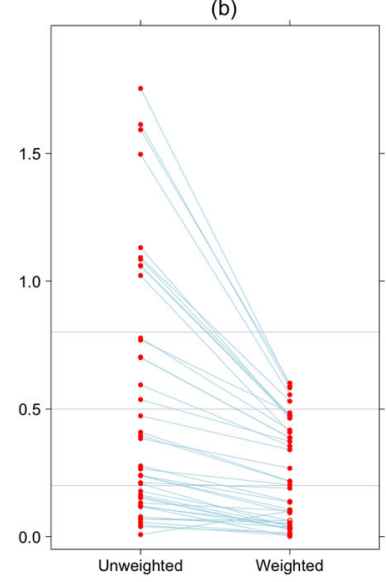

(e)

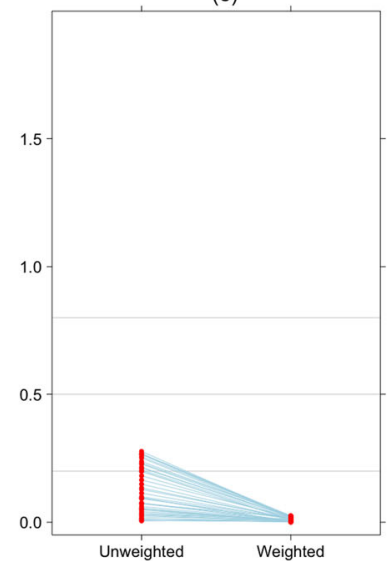

(c)

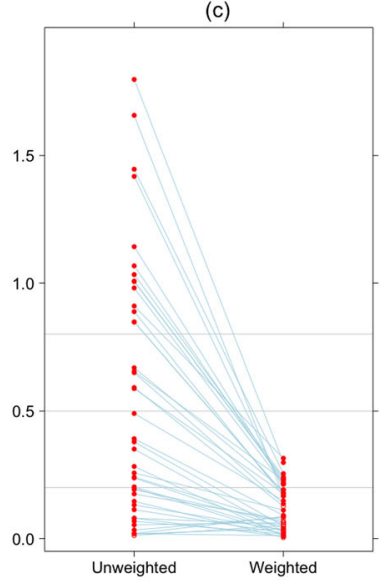

(f)

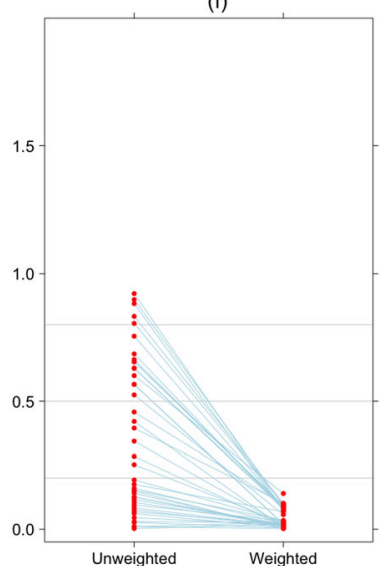

Fig. 1 Balance in demographic and other interventions for (a) Mother is primary decision maker in her healthcare, (b) any ANC intervention received, (c) Skilled attendant during birth, (d) distance is not a problem for health care, (e) early breastfeeding, and (f) postnatal health contact within 2 days of birth. The standardized difference (average difference between those who received intervention versus those who did not divided by standard error) is shown on the vertical axis, in unweighted and propensity score weighted survey samples

For these same ten interventions, we examined neonatal mortality due to IPRE, shown in Table 5. There were two interventions with apparent relationships with mortality due to IPRE after weighting with propensity scores: early breastfeeding $(0.14,95 \%$ CI $0.04-0.45)$ and delayed bathing $(0.00,95 \%$ CI $0.00-0.01)$. All of these interventions were also associated with mortality due to IPRE in the same direction prior to weighting with propensity scores. Relative risks and their 95\% confidence intervals for all-cause, infection-specific, and IPRE-specific mortality are shown in Fig. 2 for ten interventions and resources where balance of confounding factors had a standardized difference of 0.2 or lower after weighting with propensity scores.

\section{Discussion}

This study aimed to describe the effectiveness of 18 interventions for neonatal survival in Nigeria using nationally representative household surveys for measuring resource and intervention coverage and cause of death estimation. Despite considerable differences in the groups that received and did not receive interventions and resources, we were able to systematically adjust for confounding factors for ten of these interventions based on a selection of demographic factors and other interventions for neonatal survival. Among the types of mortality considered (all cause, from infections, and from IPRE) we identified multiple interventions and resources with implications for neonatal survival in Nigeria. Interventions that were not identified are not necessarily ineffective or without potential effectiveness; however, these results suggest that those identified are more effective in their current implementations.

There were interventions and resources of interest that could not be examined due to extreme imbalance in the selected confounding factors, especially for antenatal 
Table 3 Unweighted and propensity score weighted associations between MNCH interventions and all-cause neonatal mortality. Both unweighted and weighted relative risks are regression adjusted for demographic factor and remaining interventions using Poisson regression, excluding those measured only in home deliveries as indicated

\begin{tabular}{|c|c|c|c|c|c|c|}
\hline \multirow[t]{2}{*}{ Intervention } & \multicolumn{3}{|c|}{ Adjusted and Unweighted } & \multicolumn{3}{|c|}{ Adjusted and Weighted } \\
\hline & Estimated RR & $\begin{array}{l}95 \% \mathrm{Cl} \\
\text { Estimated RR }\end{array}$ & $\mathrm{p}$ & Estimated RR & $\begin{array}{l}\text { 95\% Cl } \\
\text { Estimated RR }\end{array}$ & $p$ \\
\hline \multicolumn{7}{|l|}{ Resources } \\
\hline Mother is primary decision maker & 0.78 & $(0.36,1.66)$ & 0.513 & 0.58 & $(0.30,1.14)$ & 0.114 \\
\hline Distance is not a problem for mother's health care & 1.29 & $(1.02,1.64)$ & 0.031 & 1.31 & $(1.03,1.67)$ & 0.029 \\
\hline \multicolumn{7}{|l|}{ Interventions delivered in the antenatal period } \\
\hline Iron/folate during pregnancy & 0.98 & $(0.71,1.34)$ & 0.881 & 0.94 & $(0.59,1.48)$ & 0.776 \\
\hline Any Malaria preventive therapy during pregnancy & 1.18 & $(0.92,1.52)$ & 0.202 & 1.19 & $(0.90,1.58)$ & 0.213 \\
\hline \multicolumn{7}{|l|}{ Interventions delivered in the postnatal period } \\
\hline Dry cord care (nothing on cord) ${ }^{a}$ & 1.40 & $(1.04,1.87)$ & 0.025 & 1.40 & $(1.04,1.89)$ & 0.029 \\
\hline Neonate dried after birth ${ }^{a}$ & 1.14 & $(0.85,1.54)$ & 0.379 & 1.18 & $(0.87,1.59)$ & 0.292 \\
\hline Skin-to-skin contact after birth ${ }^{a}$ & 0.86 & $(0.55,1.35)$ & 0.520 & 0.70 & $(0.42,1.18)$ & 0.185 \\
\hline Early breastfeeding (within one hour) & 0.40 & $(0.31,0.51)$ & $<0.001$ & 0.41 & $(0.32,0.52)$ & $<0.001$ \\
\hline Delayed bathing $24 \mathrm{~h}$ or more ${ }^{\mathrm{a}}$ & 1.17 & $(0.55,2.46)$ & 0.686 & 0.78 & $(0.41,1.50)$ & 0.464 \\
\hline Postnatal health contact within 2 days of birth & 0.53 & $(0.35,0.80)$ & 0.002 & 0.68 & $(0.41,1.13)$ & 0.135 \\
\hline
\end{tabular}

${ }^{a}$ Only measured for home deliveries, not included in analysis for other interventions. In addition, these interventions were not adjusted for facility delivery, as they were only measured for home births

care and for interventions related to labor and delivery. It is unfortunate that these interventions, which likely confer much benefit, could not be included in this analysis. This analysis suggests that there is a group of women and neonates in Nigeria that do not receive antenatal or labor and delivery care, who are very different demographically than those who do receive those resources and interventions. Further research is necessary into why such disparities exist in Nigeria and how these might be addressed.

Early breastfeeding and delayed bathing are indicated in these results for prevention of deaths due to IPRE, however, this evidence is likely due to unmeasured factors such as inability to suckle or death at a very early age relative to neonatal deaths from other causes. Of deaths attributable to IPRE, 30 (41\%) out of 74 occurred on the first day on life, compared to 29 (17\%) out of 171 deaths due to infection. Early breastfeeding has the strongest evidence for preventing all cause neonatal mortality, however, this result may be impacted by reverse causality, such as newborns who are born too sick to suckle due to IPRE. We repeated our anlaysis including only deaths occurring in day of life 3 or later, resulting in reduced but still notable weighted effect of early breastfeeding (relative risk $0.69,95 \%$ CI 0.49-0.95).

Our finding also indicate that women's decision making and postnatal care have the strongest evidence for preventing mortality due to infections. Women's empowerment and decision-making power play a key role in the utilization of maternal, neonatal and child health care overall [42]. The severity of infections may have triggered the decision-making process as seen in other studies [43].

Our analysis also produced a counterintuitive result about dry cord care. It is possible that estimated effectiveness of dry cord care was biased through confounding by unmeasured factors. The alternatives to dry cord care in the 2013 NDHS were oil, ash, ointment/powder, animal dung, turmeric, Dettol (topical antiseptic) or methylated spirit. Chlorhexidine is now recommended for cord care by the Nigerian Federal Ministry of Health and may have been available at the time of the 2013 NDHS; however, dry cord care was recommended at the time of the survey [25]. It is also possible that this unexpected association may be due to measurement issues; it may be more difficult for women who had sick neonates or who had difficult deliveries to have known or to remember details about cord care. We also observed counterintuitive results related to distance to travel for health care not being a problem, which unexpectedly appeared to put neonates at higher mortality risk in this analysis. Other research has indicated that proximity to health care is not related to neonatal mortality [44]. We expect this result may be due to residual confounding or 
(a)
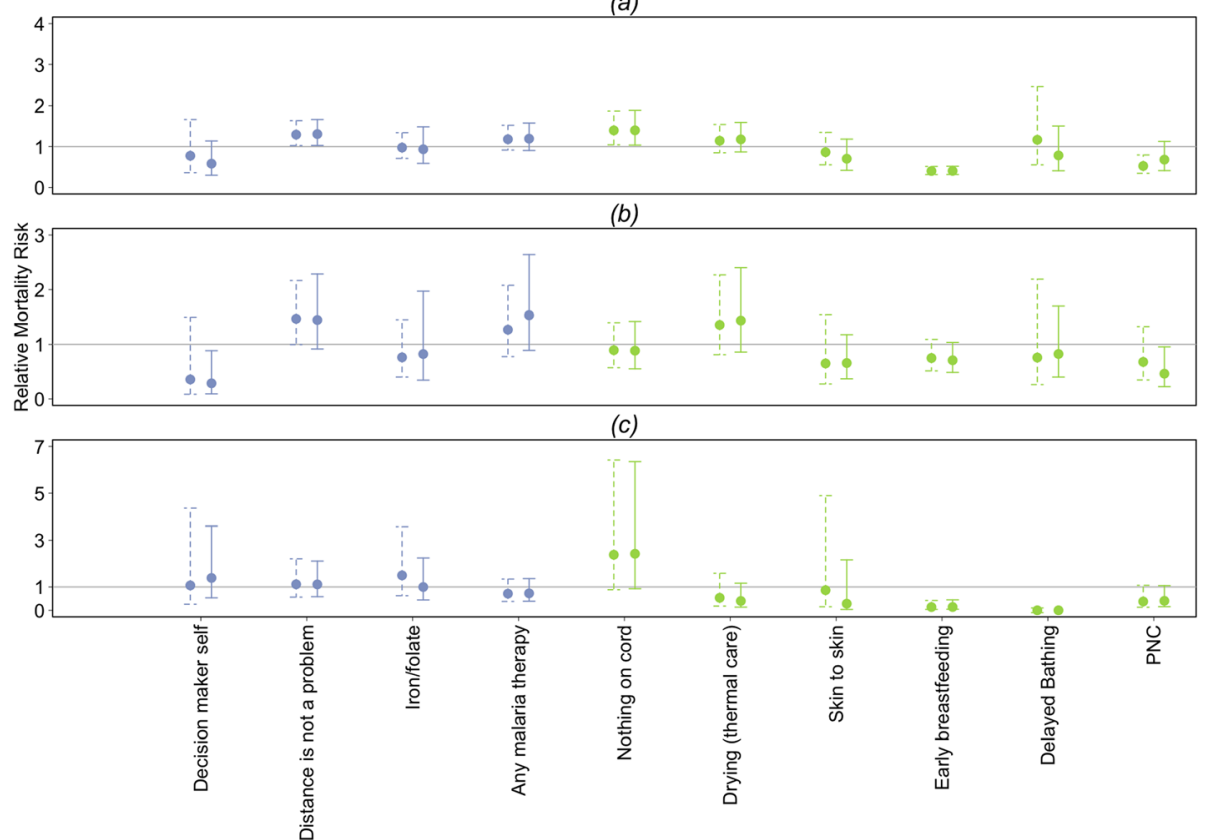

Fig. 2 Unweighted and propensity score weighted estimated relative risk for specific interventions and resources for (a) all cause neonatal mortality, (b) neonatal mortality due to infections and (c) neonatal mortality due to intra-partum related events (IPRE). Both unweighted and inverse probability of treatment weighted relative risks are adjusted for demographic factor and remaining interventions, excluding those measured only in home deliveries, estimated with Poisson regression

confounding with unmeasured factors. For example, women with complicated pregnancies may be more concerned about being far from health care.

Further details about what happens to women during their pregnancies would be a valuable addition to household surveys in analyses such as these presented here, such as if women were ill during their pregnancies or if they experienced complications during labor and delivery. Such documentation could provide valuable insight into the effectiveness of interventions, since many interventions are developed to address complications, but could also advance research on the extent of complications and the risk factors for difficult pregnancies. Future research should examine the feasibility of such reporting in household surveys. The VASA survey could serve as a model for such measurement.

Our analysis has limitations. Verbal autopsy cause assignment is not a perfect estimate for cause of death; however, verbal autopsy is likely more accurate when specifying deaths due to any infectious cause compared to death due to a specific infectious cause [41]. Given the complexities in the pathway to receiving interventions and resources, from the decision to seek care, to the receipt of care and the many factors determining quality of care, it is possible that our results are subject to residual confounding or to confounding due to unmeasured factors. Some factors of interest were available in the VASA survey, but not in the NDHS, including maternal complications during pregnancy or labor and delivery and care seeking for these, and so could not be examined for survivors. We were, however, very successful in assembling similar populations for comparison for the majority of interventions and resources of interest due to the properties of the propensity score, which has been used for estimating effectiveness of many other types of interventions [29].

We identified several interventions with the strongest evidence for promoting neonatal survival in Nigeria and similar low resource settings. Early breastfeeding, women's autonomous decision-making and access to immediate postnatal care all have effectively reduced neonatal mortality in Nigeria. These results have important implications for where future resources can most effectively be utilized to reduce neonatal mortality in Nigeria and other similar settings. As neonatal mortality continues to be a dominant fraction of under-five mortality, accessible interventions are necessary to make further progress towards the SDGs. Selecting the most appropriate and scalable interventions will be necessary for the global health community to meet the goal of reducing neonatal mortality. 
Table 4 Unweighted and propensity score weighted associations between MNCH interventions and neonatal mortality from infectious causes (diarrhea, sepsis, meningitis, pneumonia, or tetanus). Both unweighted and inverse probability of treatment weighted relative risks are adjusted for demographic factors and remaining interventions, excluding those measured only in home deliveries marked with an asterisk, using Poisson regression

\begin{tabular}{|c|c|c|c|c|c|c|}
\hline \multirow[t]{2}{*}{ Intervention } & \multicolumn{3}{|c|}{ Adjusted and Unweighted } & \multicolumn{3}{|c|}{ Adjusted and Weighted } \\
\hline & Estimated RR & $\begin{array}{l}95 \% \mathrm{Cl} \\
\text { Estimated RR }\end{array}$ & $\mathrm{p}$ & Estimated RR & $\begin{array}{l}95 \% \mathrm{Cl} \\
\text { Estimated RR }\end{array}$ & p \\
\hline \multicolumn{7}{|l|}{ Resources } \\
\hline Mother is primary decision maker & 0.36 & $(0.09,1.50)$ & 0.159 & 0.29 & $(0.09,0.88)$ & 0.030 \\
\hline Distance is not a problem for mother's health care & 0.68 & $(0.46,1.01)$ & 0.054 & 0.69 & $(0.44,1.09)$ & 0.111 \\
\hline \multicolumn{7}{|l|}{ Interventions delivered in the antenatal period } \\
\hline Iron/folate during pregnancy & 0.76 & $(0.40,1.45)$ & 0.409 & 0.82 & $(0.34,1.97)$ & 0.662 \\
\hline Any Malaria preventive therapy during pregnancy & 1.27 & $(0.78,2.08)$ & 0.343 & 1.53 & $(0.89,2.64)$ & 0.124 \\
\hline \multicolumn{7}{|l|}{ Interventions delivered in the postnatal period } \\
\hline Dry cord care (nothing on cord) ${ }^{a}$ & 0.89 & $(0.57,1.40)$ & 0.623 & 0.89 & $(0.55,1.42)$ & 0.612 \\
\hline Neonate dried after birth ${ }^{\mathrm{a}}$ & 1.36 & $(0.81,2.27)$ & 0.247 & 1.44 & $(0.86,2.40)$ & 0.168 \\
\hline Skin-to-skin contact after birth ${ }^{a}$ & 0.65 & $(0.27,1.55)$ & 0.331 & 0.66 & $(0.37,1.18)$ & 0.159 \\
\hline Early breastfeeding (within one hour) & 0.75 & $(0.51,1.09)$ & 0.133 & 0.71 & $(0.49,1.03)$ & 0.075 \\
\hline Delayed bathing $24 \mathrm{~h}$ or more ${ }^{\mathrm{a}}$ & 0.76 & $(0.26,2.19)$ & 0.610 & 0.82 & $(0.40,1.70)$ & 0.599 \\
\hline Postnatal health contact within 2 days of birth & 0.68 & $(0.35,1.32)$ & 0.256 & 0.46 & $(0.22,0.95)$ & 0.037 \\
\hline
\end{tabular}

${ }^{a}$ Only measured for home deliveries, not included in analysis for other interventions. In addition, these interventions were not adjusted for facility delivery, as they were only measured for home births

Table 5 Unweighted and propensity score weighted associations between MNCH interventions and neonatal mortality due to intrapartum events. Both unweighted and inverse probability of treatment weighted relative risks are adjusted for demographic factors and remaining interventions, excluding those measured only in home deliveries marked with an asterisk, using Poisson regression

\begin{tabular}{|c|c|c|c|c|c|c|}
\hline \multirow[t]{2}{*}{ Intervention } & \multicolumn{3}{|c|}{ Adjusted and Unweighted } & \multicolumn{3}{|c|}{ Adjusted and Weighted } \\
\hline & Estimated RR & $\begin{array}{l}\text { 95\% Cl } \\
\text { Estimated RR }\end{array}$ & $p$ & Estimated RR & $\begin{array}{l}95 \% \mathrm{Cl} \\
\text { Estimated RR }\end{array}$ & $\mathrm{p}$ \\
\hline \multicolumn{7}{|l|}{ Resources } \\
\hline Mother is primary decision maker & 1.07 & $(0.26,4.36)$ & 0.929 & 1.39 & $(0.53,3.60)$ & 0.503 \\
\hline Distance is not a problem for mother's health care & 1.12 & $(0.56,2.20)$ & 0.754 & 1.12 & $(0.58,2.14)$ & 0.740 \\
\hline \multicolumn{7}{|l|}{ Interventions delivered in the antenatal period } \\
\hline Iron/folate during pregnancy & 1.50 & $(0.63,3.58)$ & 0.365 & 1.00 & $(0.44,2.24)$ & 0.996 \\
\hline Any Malaria preventive therapy during pregnancy & 0.71 & $(0.38,1.34)$ & 0.293 & 0.73 & $(0.39,1.36)$ & 0.318 \\
\hline \multicolumn{7}{|l|}{ Interventions delivered in the postnatal period } \\
\hline Dry cord care (nothing on cord) ${ }^{a}$ & 2.38 & $(0.88,6.42)$ & 0.087 & 2.42 & $(0.92,6.35)$ & 0.073 \\
\hline Neonate dried after birth ${ }^{\mathrm{a}}$ & 0.54 & $(0.18,1.59)$ & 0.260 & 0.40 & $(0.14,1.16)$ & 0.092 \\
\hline Skin-to-skin contact after birth ${ }^{a}$ & 0.86 & $(0.15,4.89)$ & 0.867 & 0.28 & $(0.04,2.16)$ & 0.224 \\
\hline Early breastfeeding (within one hour) & 0.14 & $(0.05,0.42)$ & 0.001 & 0.14 & $(0.04,0.45)$ & 0.001 \\
\hline Delayed bathing $24 \mathrm{~h}$ or more ${ }^{\mathrm{a}}$ & 0.00 & $(0.00,0.01)$ & $<0.001$ & 0.00 & $(0.00,0.01)$ & $<0.001$ \\
\hline Postnatal health contact within 2 days of birth & 0.38 & $(0.13,1.07)$ & 0.068 & 0.41 & $(0.16,1.06)$ & 0.065 \\
\hline
\end{tabular}

${ }^{a}$ Only measured for home deliveries, not included in analysis for other interventions. In addition, these interventions were not adjusted for facility delivery, as they were only measured for home births 


\section{Supplementary information}

Supplementary information accompanies this paper at https://doi.org/10. 1186/s12884-020-03220-3.

Additional file 1. STROBE diagram to describe those contributing to analysis.

Additional file 2. The standardized difference of confounders before and after propensity score weighting for 18 interventions considered.

Additional file 3. A summary of cause of neonatal death and the ages at neonatal death.

Additional file 4. Poisson regression for the association between each of 18 interventions and all cause, IPRE, and infection related mortality.

Additional file 5. A table summarizing the considerations of analysis at all stages.

\section{Abbreviations}

ANC1: one or more antenatal care visits with a skilled provider; ANC4: at least four antenatal care visits with any provider; $\mathrm{Cl}$ : confidence interval; IPRE: intrapartum-related events; IPTp: intermittent preventive treatment of malaria in pregnancy; NDHS: Nigeria Demographic and Health Survey; PNC: postnatal care for very young neonates; SBA: skilled birth attendance; SDG: Sustainable Development Goals; VASA: Verbal and Social Autopsy Study

\section{Acknowledgments}

The authors are grateful for support from the Bill and Melinda Gates Foundation.

\section{Authors' contributions}

AK, HK, and RB conceptualized the study. AK and JP worked together on the study design. JP conducted the statistical analysis. AA, JQ, and JM reviewed and interpreted preliminary results. JP composed the initial draft. All authors reviewed and edited the final manuscript. The author(s) read and approved the final manuscript.

\section{Funding}

This research was generously supported by the Bill and Melinda Gates Foundation. The funders did not have a role in the study design, data analysis, writing of this manuscript, or in the decision to publish this research.

\section{Ethics approval and consent to participate}

The NDHS was approved by the Institutional Review Board at ICF International as well as the National Health Research Ethics Committee of Nigeria. Informed consent was given by all participants in the NDHS, and from parents or guardians for children and adolescents, emphasizing that participation is voluntary. The VASA study was approved by the National Health Research Ethics Committee of the Nigeria Federal Ministry of Health and the Institutional Review Board of the Johns Hopkins Bloomberg School of Public Health. Only women who gave permission for a return visit during the NDHS were approached for a VASA interview. Oral informed consent was sought from all participants and signed by the VASA interviewer as witness to the consent.

\section{Consent for publication}

All authors agree to the publication of this research. Not applicable for participants, since no identifying details have been included and participants maintain anonymity.

\section{Competing interests}

The authors declare that they have no competing interests.

\section{Author details}

${ }^{1}$ Institute for International Programs, Johns Hopkins Bloomberg School of Public Health, Baltimore, MD, USA. ${ }^{2}$ Center for Child and Community Health Research, Department of Pediatrics, Johns Hopkins School of Medicine, Baltimore, MD, USA. ${ }^{3}$ USAID, Abuja, Nigeria. ${ }^{4}$ Federal Ministry of Health, Abuja, Nigeria. ${ }^{5}$ UNICEF, New York, NY, USA.
Received: 14 November 2019 Accepted: 28 August 2020

Published online: 14 September 2020

\section{References}

1. UNICEF. The state of the World's children 2019. Children, Food and Nutrition: Growing well in a changing world. UNICEF, New York; 2019.

2. United Nations General Assembly. Transforming our world: the 2030 agenda for sustainable development. New York: United Nations; 2015. https://sustainabledevelopment.un.org/post2015/transformingourworld/ publication (accessed May 1, 2020).

3. Liu L, Oza S, Hogan D, Chu Y, Perin J, Zhu J, Lawn JE, Cousens S, Mathers C, Black RE. Global, regional, and national causes of under-5 mortality in 200015: an updated systematic analysis with implications for the sustainable development goals. Lancet. 2017 Jan 6;388(10063):3027-35.

4. Darmstadt GL, Bhutta ZA, Cousens S, Adam T, Walker N, De Bernis L. Lancet neonatal survival steering Team. Evidence-based, cost-effective interventions: how many newborn babies can we save? Lancet. 2005 Mar 12;365(9463):977-88.

5. Roberts D, Brown J, Medley N. Dalziel SR. The Cochrane Library: Antenatal corticosteroids for accelerating fetal lung maturation for women at risk of preterm birth; 2017 Jan 1.

6. World Health Organization. "Every newborn: an action plan to end preventable deaths." (2014).

7. Boundy EO, Dastjerdi R, Spiegelman D, Fawzi WW, Missmer SA, Lieberman E, Kajeepeta S, Wall S, Chan GJ. Kangaroo mother care and neonatal outcomes: a meta-analysis. Pediatrics. 2015 Dec 23:peds-2015.

8. Edmond KM, Zandoh C, Quigley MA, Amenga-Etego S, Owusu-Agyei S, Kirkwood BR. Delayed breastfeeding initiation increases risk of neonatal mortality. Pediatrics. 2006 Mar 1;117(3):e380-6.

9. Sinha A, Sazawal S, Pradhan A, Ramji S. Opiyo N. The Cochrane Library: Chlorhexidine skin or cord care for prevention of mortality and infections in neonates; 2015 Jan 1.

10. Mullany LC, Darmstadt GL, Khatry SK, Katz J, LeClerq SC, Shrestha S, Adhikari R, Tielsch JM. Topical applications of chlorhexidine to the umbilical cord for prevention of omphalitis and neonatal mortality in southern Nepal: a community-based, cluster-randomised trial. Lancet. 2006 Mar 18;367(9514):910-8.

11. Doku DT, Neupane S. Survival analysis of the association between antenatal care attendance and neonatal mortality in 57 low-and middle-income countries. Int J Epidemiol. 2017 Jul 13;46(5):1668-77.

12. Fink G, Ross R, Hill K. Institutional deliveries weakly associated with improved neonatal survival in developing countries: evidence from 192 demographic and health surveys. Int J Epidemiol. 2015;44(6):1879-88.

13. Singh $K$, Brodish $P$, Suchindran C. A regional multilevel analysis: can skilled birth attendants uniformly decrease neonatal mortality? Matern Child Health J. 2014;18(1):242-9.

14. Singh K, Brodish P, Haney E. Postnatal care by provider type and neonatal death in sub-Saharan Africa: a multilevel analysis. BMC Public Health. 2014;14(1):941.

15. Baqui AH, Ahmed S, El Arifeen S, Darmstadt GL, Rosecrans AM, Mannan I, Rahman SM, Begum N, Mahmud AB, Seraji HR, Williams EK. Effect of timing of first postnatal care home visit on neonatal mortality in Bangladesh: a observational cohort study. BMJ. 2009 Aug 14;339:b2826.

16. Pennington A, Orton L, Nayak S, Ring A, Petticrew M, Sowden A, White $M$, Whitehead $M$. The health impacts of women's low control in their living environment: a theory-based systematic review of observational studies in societies with profound gender discrimination. Health \& Place 2018 May 31;51:1-0.

17. Escamilla V, Calhoun L, Winston J, Speizer IS. The role of distance and quality on facility selection for maternal and child health Services in Urban Kenya. J Urban Health. 2018 Feb 1;95(1):1-2.

18. Integrated Maternal Newborn and Child Health Strategy. Federal Ministry of Health, Nigeria, 2015.

19. Findley SE, Uwemedimo OT, Doctor HV, Green C, Adamu F, Afenyadu GY. Early results of an integrated maternal, newborn, and child health program, northern Nigeria, 2009 to 2011. BMC Public Health. 2013 Dec;13(1):1034.

20. Barros FC, Bhutta ZA, Batra M, Hansen TN, Victora CG, Rubens CE. Global report on preterm birth and stillbirth (3 of 7): evidence for effectiveness of interventions. BMC Pregnancy and Childbirth. 2010 Feb;10(1):S3.

21. National Population Commission (NPC) [Nigeria] and ICF International. 2014 Nigeria Demographic and Health Survey. Abuja, Nigeria, and Rockville. 
Maryland, USA: NPC and ICF International; 2013. https://dhsprogram.com/ pubs/pdf/fr293/fr293.pdf

22. National Population Commission (NPC) [Nigeria]. A verbal/social autopsy study. Nigeria, NPC: Abuja; 2014. https://www.healthynewbornnetwork.org/ hnn-content/uploads/Nigeria_2014-VASA-Study_final_report.pdf.

23. Adewemimo A, Kalter HD, Perin J, Koffi AK, Quinley J, Black RE. Direct estimates of cause-specific mortality fractions and rates of under-five deaths in the northern and southern regions of Nigeria by verbal autopsy interview. PLoS One. 2017 May 31;12(5):e0178129.

24. Freedman DA. On regression adjustments to experimental data. Adv Appl Math. 2008:40(2):180-93.

25. ICF International. Demographic and health survey sampling and household listing manual. MEASURE DHS, Calverton, Maryland, U.S.A.: ICF International; 2012.

26. Moxon SG, Ruysen H, Kerber KJ, Amouzou A, Fournier S, Grove J, Moran AC, Vaz LM, Blencowe H, Conroy N, Gülmezoglu AM. Count every newborn; a measurement improvement roadmap for coverage data. BMC Pregnancy and Childbirth. 2015 Sep 11;15(2):S8

27. Sitrin D, Perin J, Vaz LM, Carvajal-Aguirre L, Khan SM, Fishel J, Amouzou A. Evidence from household surveys for measuring coverage of newborn care practices. Journal of Global Health. 2017 Dec;7(2).

28. Boerma JT, Bryce J, Kinfu Y, Axelson H, Victora CG. Mind the gap: equity and trends in coverage of maternal, newborn, and child health services in 54 Countdown countries. The Lancet (London, England). 2008 Apr;371(9620): 1259-67.

29. Thoemmes FJ, Kim ES. A systematic review of propensity score methods in the social sciences. Multivar Behav Res. 2011 Feb 7;46(1):90-118.

30. Austin PC. The performance of different propensity score methods for estimating marginal hazard ratios. Stat Med. 2013;32(16):2837-49.

31. Zhu Y, Schonbach M, Coffman DL, Williams JS. Variable selection for propensity score estimation via balancing covariates. Epidemiology. 2015 Mar 1;26(2):e14-5.

32. DuGoff EH, Schuler M, Stuart EA. Generalizing observational study results: applying propensity score methods to complex surveys. Health Serv Res. 2014 Feb 1;49(1):284-303.

33. Rosenbaum PR, Rubin DB. The central role of the propensity score in observational studies for causal effects. Biometrika. 1983;70(1):41-55.

34. Austin PC, Stuart EA. Moving towards best practice when using inverse probability of treatment weighting (IPTW) using the propensity score to estimate causal treatment effects in observational studies. Stat Med. 2015; 34(28):3661-79.

35. Frome EL. The analysis of rates using Poisson regression models. Biometrics. 1983 Sep; $1: 665-74$.

36. Lumley T, Scott A. Fitting regression models to survey data. Stat Sci. 2017; 32:265-78.

37. Korn EL, Graubard BI. Epidemiologic studies utilizing surveys: accounting for the sampling design. Am J Public Health. 1991 Sep;81(9):1166-73.

38. Zou G. A modified poisson regression approach to prospective studies with binary data. Am J Epidemiol. 2004 Apr 1;159(7):702-6.

39. Core Team R. R: a language and environment for statistical computing. Vienna, Austria: R Foundation for Statistical Computing; 2016.

40. Austin PC. Balance diagnostics for comparing the distribution of baseline covariates between treatment groups in propensity-score matched samples. Stat Med. 2009;28(25):3083-107.

41. Kalter HD, Perin J, Black RE. Validating hierarchical verbal autopsy expert algorithms in a large data set with known causes of death. Journal of Global Health. 2016 Jun;6(1).

42. Mohan, D., Gupta, S., LeFevre, A., Bazant, E., Killewo, J., \& Baqui, A. H. (2015) Determinants of postnatal care use at health facilities in rural Tanzania: multilevel analysis of a household survey. BMC pregnancy and childbirth, 15, 282. https://doi.org/10.1186/s12884-015-0717-7.

43. Allen K. A. (2014). Parental decision-making for medically complex infants and children: an integrated literature review. Int J Nurs Stud, 51(9), 12891304. https://doi.org/10.1016/j.jpurstu.2014.02.003.

44. Lohela TJ, Campbell OM, Gabrysch S. Distance to care, facility delivery and early neonatal mortality in Malawi and Zambia. PLoS One. 2012 Dec 27; 7(12):e52110.

\section{Publisher's Note}

Springer Nature remains neutral with regard to jurisdictional claims in published maps and institutional affiliations.

Ready to submit your research? Choose BMC and benefit from:

- fast, convenient online submission

- thorough peer review by experienced researchers in your field

- rapid publication on acceptance

- support for research data, including large and complex data types

- gold Open Access which fosters wider collaboration and increased citations

- maximum visibility for your research: over $100 \mathrm{M}$ website views per year

At BMC, research is always in progress.

Learn more biomedcentral.com/submissions 